\title{
Complementary and Alternative Therapies Used by Turkish Breast Cancer Patients Undergoing Chemotherapy
}

\author{
Gulbeyaz Can ${ }^{a}$ Melike Demir ${ }^{b}$ Adnan Aydiner ${ }^{c}$ \\ astanbul University, Nursing Faculty, Istanbul,

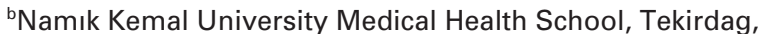 \\ 'Istanbul University, Institute of Oncology, Istanbul, Turkey
}

\section{Keywords}

Breast cancer - Chemotherapy .

Complementary and alternative medicine $\cdot$ CAM

\section{Summary}

Background: Most breast cancer patients use complementary and alternative medicine (CAM), usually in parallel with their conventional treatments. This study was planned to determine the prevalence and determining factors for use of CAM by breast cancer patients undergoing chemotherapy. Patients and Methods: This descriptive study was carried out between October 2010 and May 2011, and included 96 patients at the Istanbul University Institute of Oncology. The Patient Characteristics form and Complementary and Alternative Medicine Scale were used for data collection. Descriptive and nonparametric tests were performed, and logistic regression analysis was used to predict factors affecting CAM use. Results: Praying was the most frequently used form of CAM, and most of the herbal supplements used by patients were harmless. Herbal use was higher among patients who had local disease (relative risk (RR) $4.48 \%$, 95\% confidence interval (Cl) 1.12-17.95), and worship was more common among those who had not undergone surgery (RR 4.66\%, 95\% Cl 1.64-13.20). Conclusion: The CAM approaches used by patients were found to be safe. However, sage and flax seed usage for estrogenand progesterone-positive patients and exercise for patients with spinal metastasis can be inappropriate approaches. It is important to question and inform patients about CAM use during treatment.

\author{
Schlüsselwörter \\ Mammakarzinom · Chemotherapie . \\ Komplementär- und Alternativmedizin · CAM
}

\section{Zusammenfassung}

Hintergrund: Die meisten Mammakarzinompatientinnen wenden Methoden der Komplementär- und Alternativmedizin (CAM) an. Dies geschieht zumeist parallel zu konventionellen Therapien. Die vorliegende Studie wurde geplant, um die Prävalenz und ausschlaggebenden Faktoren für den Einsatz von CAM durch Mammakarzinompatientinnen unter chemotherapeutischer Behandlung zu bestimmen. Patienten und Methoden: Die deskriptive Studie wurde zwischen Oktober 2010 und Mai 2011 durchgeführt und umfasste 96 Patientinnen des Istanbul University Institute of Oncology. Zur Datensammlung kamen das Patient-Characteristics-Formular und die Complementary-and-Alternative-Medicine-Skala zum Einsatz. Deskriptive und nichtparametrische Tests wurden durchgeführt, und die logistische Regressionsanalyse wurde zur Vorhersage von Faktoren, die die Anwendung von CAM beeinflussen, eingesetzt. Ergebnisse: Beten war die am häufigsten angewendete CAMMethode, und die meisten zum Einsatz kommenden pflanzlichen Nahrungsergänzungsmittel waren harmlos. Kräuter wurden häufiger von Patientinnen mit lokaler Erkrankung verwendet (relatives Risiko (RR) 4,48\%, 95\%-Konfidenzinterval (KI) 1,12-17,95), und religiöse Aktivitäten wurden häufiger von Patientinnen, die nicht chirurgisch behandelt worden waren, ausgeübt (RR 4,66\%, 95\%-KI 1,64-13,20). Schlussfolgerung: Die von den Patientinnen angewendeten CAM-Methoden stellten sich als sicher heraus. Die Einnahme von Salbei und Leinsamen durch östrogen- und progesteron-positive Patientinnen sowie Sport bei Patientinnen mit Spinalmetastasen können jedoch unangebracht sein. Es ist wichtig, Patientinnen zur Anwendung von CAM während der Behandlung zu befragen und zu informieren.

\section{KARGER \\ Fax +497614520714 \\ Information@Karger.de}

www.karger.com (c) 2012 S. Karger GmbH, Freiburg

$1661-3791 / 12 / 0076-0471 \$ 38.00 / 0$

Accessible online at:

www.karger.com/brc
Gulbeyaz Can, BSc., MSc., PhD., Assoc. Prof.

Istanbul Universitesi Hemşirelik Fakültesi

Abide-i-Hurriyet cad. 34387 Sisli, Istanbul, Turkey

gulbeyaz@istanbul.edu.tr 


\section{Introduction}

Breast cancer is the leading malignancy and the second most common cause of cancer-related deaths among women. After diagnosis, many women want to know what proactive steps they can take in addition to conventional therapies to positively impact their prognosis. They may therefore make lifestyle changes, and some adopt different forms of complementary and alternative medicine (CAM) [1-4]. Although the average prevalence and characteristics of CAM use in breast cancer patients varies internationally, the incidence in Turkey was reported to be around $33 \%$. Most of our patients use various forms of CAM, including herbal remedies, prayer/spiritual healing, dietary/nutritional therapies, exercise, musical therapy, massage, meditation, and acupuncture [5, 6]. However, recent surveys in breast cancer patients showed that biologically-based practices (e.g., herbs, vitamins, foods) were the most common types of CAM used by women with breast cancer, followed by mind-body approaches such as prayer, meditation, and spiritual healing. It was reported that energy medicine (e.g., Qi gong, Reiki) and whole medical systems such as naturopathy, homeopathy, and traditional Chinese medicine were less likely to be used by women with breast cancer [7].

The use of biologically-based complementary therapies such as herbs and other dietary supplements is popular among breast cancer patients [5-7]. Most users expect the supplements to help cancer treatment or reduce side effects, but such expectations are often unrealistic and unmet. Although diet may contribute to cancer prevention, the role of individual dietary supplementation, except for green tea, in preventing cancer or its recurrence has still not been proven $[8,9]$. Sometimes, the concurrent use of supplements, especially high-dose antioxidants or complex botanical agents, during chemotherapy or radiation therapy can be problematic because of drug-supplement interactions. Therefore, patients should be queried about their use of dietary supplements, in particular herbal products, prior to starting cancer treatment, in order to assess possible side effects and potential interactions with other drugs [8].

Mind-body modalities are recommended as part of a multidisciplinary approach to reduce anxiety, mood disturbance, chronic pain, and improve quality of life (QoL) in cancer patients [8]. It may be helpful for clinicians to address spirituality, in particular with survivors of breast cancer [10], because religious/spiritual coping strategies may serve multiple functions in the long-term adjustment to cancer, such as maintaining self-esteem, providing a sense of meaning and purpose, giving emotional comfort, and providing a sense of hope [11]. Recent findings indicate that behavioral techniques and physical exercise improve psychosocial functioning and QoL in breast cancer patients and survivors [12].

Energy therapies based on a philosophy of bioenergy fields are safe and may provide some benefit in reducing stress and enhancing QoL. There is limited evidence of their efficacy in symptom management, including reducing pain and fatigue [8]. Acupoint stimulation is strongly recommended as a complementary therapy for chemotherapy-induced nausea and vomiting, but its value in managing other distress symptoms, such as joint pain related to adjuvant aromatase inhibitors, postmastectomy edema, leukopenia, and hot flushes, has not been established. A previous review concluded that the evidence for such effects was still not strong enough when the methodological quality was taken into consideration [13].

Against the backdrop of the findings reported above, this study examined the following questions: i) What kinds of CAM therapies are used by Turkish breast cancer patients during chemotherapy? ii) Are the CAM therapies used by Turkish breast cancer patients safe? iii) Which personal- and illness-related variables predict CAM use by Turkish breast cancer patients during chemotherapy?

\section{Patients and Methods}

\section{Research Setting and Sample}

This descriptive study was carried out between October 2010 and May 2011 at the Istanbul University Institute of Oncology. Inclusion criteria were as follows: patients diagnosed with breast cancer who were receiving adjuvant chemotherapy or chemotherapy for metastatic disease; older than 18 years of age; able to communicate in Turkish; and consenting to participate in the study. Patients who had a social or psychological status that would prevent them from participating in the study and patients who did not wish to participate in the study after being informed of it were excluded. Approximately 140 patients with breast cancer received chemotherapy during the study. According to power analysis and sample size calculations, confidence interval (CI) and CAM use were determined to be $95 \%$ and $33 \%$, respectively, while a minimum sample size of 75 was determined in this study which was conducted in Turkey and included 96 patients.

\section{Data Collection}

Patients meeting the inclusion criteria were invited to participate, and informed consent was obtained. A face-to-face interview was performed during treatment, and patients' personal- and illness-related characteristics were evaluated using a Patient Characteristics form. Patients who were well enough then completed the Complementary and Alternative Medicine Scale (CAM Scale) themselves; for those who were too weak to do so, a friend or relative of the patient was asked to assist by verbally presenting the questions to the patient and completing the CAM Scale form according to the patient's responses. The Patient Characteristics form was developed by the authors and contains 25 items that address demographic (e.g., age, income level, employment status), disease, and treatment characteristics at the time of the initial diagnosis (e.g., surgical therapy, radiation therapy, chemotherapy). An updated version of the CAM Scale [14], developed by the authors, was used to evaluate the CAM interventions used by breast cancer patients during chemotherapy. This assessment scale comprises 75 CAM interventions frequently used by cancer patients: energy therapies ( 2 items), mind-body interventions (mind-body practices and religious practices) (14 items), biologicallybased approaches (herbal and dietary supplements) (50 items), manipulative approaches (6 items), and whole medical systems (3 items). In this scale, the use of each CAM method was assessed using dichotomous responses, where 0 was 'no', and 1 was 'yes'. The Kuder-Richardson 20 (KR20) coefficient for the scale was 0.84 . 
Table 1. Demographic patient characteristics $(n=96)$

\begin{tabular}{lc}
\hline & Patients, $\mathrm{n}(\%)$ \\
\hline Marital status & $79(82.3)$ \\
Married & $17(17.7)$ \\
Single/widowed & \\
Educational level & $3(3.1)$ \\
Illiterate & $15(15.6)$ \\
Literate & $38(39.6)$ \\
Primary school & $20(20.8)$ \\
Secondary school & $16(16.7)$ \\
High school & $4(4.2)$ \\
College & $61(63.5)$ \\
Profession & $16(16.7)$ \\
Housewife & $6(6.2)$ \\
Retired & $13(13.5)$ \\
Self-employed & \\
Salaried & $11(11.5)$ \\
Employment status & $85(88.5)$ \\
Working & \\
Not working & $9(9.4)$ \\
Income level & $87(90.6)$ \\
Low income &
\end{tabular}

Table 2. Disease and treatment-related patient characteristics $(n=96)$

\begin{tabular}{lc}
\hline & Patients, $\mathrm{n}(\%)$ \\
\hline Health insurance & $3(3.1)$ \\
Yes & $93(96.9)$ \\
No & $52(54.2)$ \\
Disease status & $44(45.8)$ \\
Primary & \\
Metastatic & $74(77.1)$ \\
Operation status & $22(22.9)$ \\
Yes & \\
No & $46(47.9)$ \\
Radiotherapy status & $48(50.0)$ \\
Yes & \\
No &
\end{tabular}

\section{Ethical Considerations}

The study was approved by the administration of the Istanbul University Institute of Oncology. Participants were informed of the study, and verbal consent was obtained.

\section{Statistical Analysis}

SPSS version 11.5 (SPSS Inc., Chicago, IL, USA) was used for data analysis. Descriptive statistics as mean, median, frequency, and percentage were used to show the distribution of the socio-demographic and illnessor treatment-related characteristics of the patients. Comparisons were made using the chi-square test, Mann-Whitney U test, and the KruskalWallis test. The relationships were evaluated with Spearman's rho correlations. Logistic regression analysis was used to examine the impact of clinical and treatment variables on the incidence of CAM use. For all statistical analyses, a 2 -sided $\mathrm{p}$ value of less than 0.05 was considered statistically significant.

\section{Results}

\section{Patient Characteristics and Disease-Related Findings}

The mean age of the patients was $50.14 \pm 11.07$ years. Of the patients undergoing chemotherapy, $60.4 \%$ were primary school graduates, $82.3 \%$ were married, $90.6 \%$ had a medium
Table 3. Use of complementary and alternative therapies $(n=96)$

\begin{tabular}{|c|c|}
\hline & Patients, n (\%) \\
\hline \multicolumn{2}{|l|}{ Energy therapies } \\
\hline Exercise & $29(30.2)$ \\
\hline \multicolumn{2}{|l|}{ Mind-body interventions } \\
\hline Praying & $74(77.1)$ \\
\hline Worship & $31(32.3)$ \\
\hline Meditation & $5(5.2)$ \\
\hline Prayer support & $3(3.1)$ \\
\hline Visit to saint & $3(3.1)$ \\
\hline Amulet & $1(1.0)$ \\
\hline \multicolumn{2}{|l|}{ Biological approaches } \\
\hline Linden & $46(47.9)$ \\
\hline Green tea & $36(37.5)$ \\
\hline Carrots & $35(36.5)$ \\
\hline Rosehip & $31(32.3)$ \\
\hline Pomegranate juice & $30(31.2)$ \\
\hline Thyme & $23(24.0)$ \\
\hline Mulberry molasses & $22(22.9)$ \\
\hline Grape seed extract & $18(18.8)$ \\
\hline Chamomile & $18(18.8)$ \\
\hline Carob molasses & $15(15.6)$ \\
\hline Black seed & $13(13.5)$ \\
\hline Almond & $13(13.5)$ \\
\hline Ginger & $12(12.5)$ \\
\hline Stinging & $11(11.5)$ \\
\hline Omega-3 & $9(9.4)$ \\
\hline Sage & $8(8.3)$ \\
\hline Turmeric & $6(6.3)$ \\
\hline Vitamins & $6(6.3)$ \\
\hline Garlic & $5(5.2)$ \\
\hline Ginseng & $3(3.1)$ \\
\hline Flax seed & $3(3.1)$ \\
\hline Yarrow & $3(3.1)$ \\
\hline Mistletoe & $3(3.1)$ \\
\hline Mallow & $3(3.1)$ \\
\hline Blueberry & $2(2.1)$ \\
\hline Soybean & $1(1.0)$ \\
\hline Lavandula stoechas & $1(1.0)$ \\
\hline St. John's wort & $1(1.0)$ \\
\hline Royal jelly & $1(1.0)$ \\
\hline Manipulative approaches & not used \\
\hline Alternative medical systems & not used \\
\hline
\end{tabular}

level income, $63.5 \%$ were housewives, and $45.8 \%$ had metastatic disease (tables 1 and 2).

\section{Overview of CAM Use}

Praying $(77.1 \%)$ was the most common CAM method used by patients. Most of the herbal supplements used by the patients were harmless. However, some of the approaches may be inappropriate, such as the use of estrogen-rich sage $(8.3 \%)$ among estrogen-positive breast cancer patients, and worship $(32.3 \%)$ or exercise $(30.2 \%)$ for patients with spinal metastasis (table 3 ).

\section{Determinants of CAM Use}

According to univariate analysis, the determinants of CAM use were found to be marital status and disease status for herbal supplement use, and prior surgery for use of worship. The use of herbal supplements was higher in patients who were married $\left(\mathrm{z}_{\mathrm{MwU}}=-2.23 ; \mathrm{p}=0.03\right)$ or had a primary disease diagnosis $\left(\chi^{2}=5.85 ; \mathrm{p}=0.02\right)$, and worship was higher in patients who had not undergone surgery $\left(\chi^{2}=9.37 ; \mathrm{p}=0.002\right)$. However, multivariate analysis showed that disease status 
and prior surgery were the only predictive factors for herbal supplement use and worship, respectively. Herbal supplement use was higher in patients who had local disease (relative risk (RR) 4.48\%; 95 CI 1.12-17.95), and worship was more common in patients who had not undergone surgical intervention (RR 4.66\%; 95 CI 1.64-13.20).

\section{Discussion}

A substantial proportion of breast cancer patients use CAM, usually in parallel with their conventional treatments $[2,7]$, and recent surveys in Turkey suggested that approximately $33 \%$ of breast cancer patients try some form of CAM, many hoping for a cure $[5,6]$. However, complementary methods are not administered to cure such diseases; rather, they may help control symptoms and improve well-being [2].

Many cancer patients believe that stress plays an important role in the etiology and progression of their disease. Although the role of stress in cancer remains controversial, cancerrelated psychological changes could be significant enough to affect not only the immediate health of the patient but also the course of the disease and thus the future health of the patient [8]. Most breast cancer patients use religion to help them cope with cancer, and research indicates that it may be helpful for clinicians to address spirituality with breast cancer patients $[10,15]$. Praying was the most frequently used CAM method among our patients. This result is consistent with the findings of previous studies regarding Muslim patients with breast cancer, which suggested that most patients resorted to religious practices during their fight against cancer $[6,16]$. Although a previous study suggested that a malignant tumor that necessitates disfiguring surgery or affects the sexuality or self-esteem of the patient in a negative way might result in the patient resorting to religious or spiritual practices [17], in the present study worship was more common among patients who did not have surgical intervention, because they believe that whatever happens comes from God. At the same time, worshipping may be impractical for patients with spinal metastasis; questioning and informing patients about this matter is important during the course of treatment.

Empirical research has documented that the use of biologically-based complementary therapies, such as herbs and other dietary supplements, is popular among breast cancer patients, as found in our study [7]. Although most of the herbal supplements used by our patients were harmless, some of the estrogen-rich approaches such as sage, flax seed, and soy bean may be impractical, especially for estrogen-positive breast cancer patients. The concurrent use of supplements, especially highdose antioxidants or complex botanical agents, during chemotherapy or radiation therapy can be problematic because of drug-supplement interactions. For example, ginger and garlic have anticoagulant effects; St. John's wort induces cyto- chrome P-450 [8]; Evidence indicates that green tea consumption may help prevent breast cancer recurrence in early stage (I/II) cancers. However, it is not possible to draw conclusions on the potential therapeutic application of green tea due to the small number of studies conducted, the lack of clinical trial evidence, the lack of a consistent dose-response relationship, and the potential for interaction with standard care [9]. Therefore, this study showed that, to assess potential side effects and interactions with other drugs, it is important for breast cancer patients to be queried and informed about the use of herbal therapies prior to starting cancer treatment with respect to disease status.

Research on physical activity and exercise in cancer patients and survivors has increased dramatically in the past decade. Most researchers have focused on the effect of exercise on QoL, physical functioning, emotional well-being, and fatigue, and included health-related outcomes such as cardiovascular fitness, muscular strength, and objective physical functioning $[8,18]$. McNeely et al. [18] conducted a systematic review and meta-analysis of 14 randomized controlled trials involving exercise interventions in 717 breast cancer survivors aged 35-72 years; 156 pooled data from these trials showed significant positive effects of exercise on QoL, cardiorespiratory fitness, and cardiovascular fitness. The pooled data also demonstrated a statistically significant impact on fatigue reduction, but only during the survivorship phase [18]. Several subsequent large-scale exercise trials provide further support for exercise as a supportive care intervention in breast cancer survivors [18]; however, only about one-third of our patient group use exercise as complementary therapy. This is an important issue that healthcare providers should address. In addition, it confirms that health professionals need to communicate with patients and learn more about exercise use among women with breast cancer.

Previous studies reported that young age, higher educational level, higher income, being married, having private health insurance, and being involved in a support group were more likely to be positively correlated with CAM use in women with breast cancer. However, other studies reported no relationship between these variables [7]. In general, we found that the use of herbal supplements was more common among patients who were married or had a local disease diagnosis, and worship was higher in patients who did not have surgical intervention. Some studies also revealed that married women were more likely to use CAM than those who were single; however, other studies showed no relationship between marital status and CAM use [7, 6, 19]. On the other hand, cancer-related conditions, type of surgery, and type of treatment for breast cancer were not associated with CAM usage [20]. Therefore, the empirical findings about how marital status, status of disease, and surgery relate to CAM use in women with breast cancer should be explored in future studies. 


\section{Conclusions}

The results of this study were consistent with the results of other studies that assessed the use of CAM approaches by breast cancer patients and found that a substantial proportion of these patients use CAM, usually in parallel with their conventional treatments $[1,7,21,22]$. Most of the CAM approaches used by our patients were found to be safe. However, sometimes sage and flax seed usage for estrogen- and progesterone-positive patients and exercise for patients with spinal metastasis can be inappropriate approaches. Therefore, questioning and informing patients of CAM use during the course of treatment is important.

\section{Acknowledgement}

This study was supported by the Istanbul University Department of Scientific Research Projects (project no. 20701).

\section{Disclosure Statement}

No conflict of interest exits, and the manuscript is approved by all authors for publication.

\section{References}

1 Hann D, Baker F, Denniston M, Entrekin N: Long-term breast cancer survivors' use of complementary therapies: perceived impact on recovery and prevention of recurrence. Integr Cancer Ther 2005;4:14-20.

2 Ernst E, Schmidt K, Baum M: Complementary/ alternative therapies for the treatment of breast cancer. A systematic review of randomized clinical trials and a critique of current terminology. Breast J 2006;12:526-530.

> Greenlee H, Kwan ML, Ergas IJ, Sherman KJ, Krathwohl SE, Bonnell C, Lee MM, Kushi LH: Complementary and alternative therapy use before and after breast cancer diagnosis: the pathways study. Breast Cancer Res Treat 2009; 117:653-665.

4 Pedersen C, Christensen S, Jensen A, Zachariae R: Prevalence, socio-demographic and clinical predictors of post-diagnostic utilisation of different types of complementary and alternative medicine (CAM) in a nationwide cohort of Danish women treated for primary breast cancer. Eur J Cancer 2009;45:3172-3181.

$\checkmark 5$ Tarhan MO, Muslu U, Somali I, Erten C, Alacacioglu A, Varol S, Aslan S: An analysis of the use of complementary and alternative therapies in patients with breast cancer. Breast Care 2009;4:301-307.

6 Gulluoglu BM, Cingi A, Cakir T, Barlas A: Patients in northwestern Turkey prefer herbs as complementary medicine after breast cancer diagnosis. Breast Care 2008;3:269-273.

$\checkmark 7$ Wanchai A, Armer JM, Stewart BR: Complementary and alternative medicine use among women with breast cancer: a systematic review. Clin J Oncol Nurs 2010;14:E45-55.
8 Deng GE, Frenkel M, Cohen L, Cassileth BR, Abrams DI, Capodice JL, Courneya KS, Dryden T, Hanser S, Kumar N, Labriola D, Wardell DW, Sagar S; Society for Integrative Oncology: Evidence-based clinical practice guidelines for integrative oncology: complementary therapies and botanicals. J Soc Integr Oncol 2009;7:85-120.

$\checkmark 9$ Seely D, Mills EJ, Wu P, Verma S, Guyatt GH: The effects of green tea consumption on incidence of breast cancer and recurrence of breast cancer: a systematic review and meta-analysis. Integr Cancer Ther 2005;4:144-155.

10 Purnell JQ, Andersen BL, Wilmot JP: Religious practice and spirituality in the psychological adjustment of survivors of breast cancer. Couns Values 2009;53:165.

11 Thuné-Boyle IC, Stygall JA, Keshtgar MR, Newman SP: Do religious/spiritual coping strategies affect illness adjustment in patients with cancer? A systematic review of the literature. Soc Sci Med 2006;63:151-164.

12 Duijts SF, Faber MM, Oldenburg HS, van Beurden M, Aaronson NK: Effectiveness of behavioral techniques and physical exercise on psychosocial functioning and health-related quality of life in breast cancer patients and survivors - a meta-analysis. Psychooncology 2011;20:115-126.

13 Chao LF, Zhang AL, Liu HE, Cheng MH, Lam HB, Lo SK: The efficacy of acupoint stimulation for the management of therapy-related adverse events in patients with breast cancer: a systematic review. Breast Cancer Res Treat 2009; 118:255-267.

14 Can G, Erol O, Topuz E, Aydiner A: Quality of life and complementary and alternative medicine use among cancer patients in Turkey. Eur J Oncol Nurs 2009;13:287-294.
15 Johnson S, Spilka B: Coping with breast cancer: the roles of clergy and faith. J Relig Health 1991; 30:21-33.

16 Montazeri A, Sajadian A, Ebrahimi M, Haghighat S, Harirchi I: Factors predicting the use of complementary and alternative therapies among cancer patients in Iran. Eur J Cancer Care 2007;16: 144-149.

17 Cella DF, Tross S: Psychological adjustment to survival from Hodgkin's disease. J Consult Clin Psychol 1986;54:616-622.

18 McNeely ML, Campbell KL, Rowe BH, Klassen TP, Mackey JR, Courneya KS: Effects of exercise on breast cancer patients and survivors: a systematic review and meta-analysis. CMAJ 2006; 175:34-41.

19 Chen Z, Gu K, Zheng Y, Zheng W, Lu W, Shu XO: The use of complementary and alternative medicine among Chinese women with breast cancer. J Altern Complement Med 2008;14:1049-1055.

20 Carpenter CL, Ganz A, Bernstein L: Complementary and alternative therapies among very longterm breast cancer survivors. Breast Cancer Res Treat 2009;116:387-396.

21 Boon HS, Olatunde F, Zick SM: Trends in complementary/alternative medicine use by breast cancer survivors: comparing survey data from 1998 and 2005. BMC Womens Health 2007;7:1-7.

22 Gerber B, Scholz C, Reimer T, Briese V, Janni W: Complementary and alternative therapeutic approaches in patients with early breast cancer: a systematic review. Breast Cancer Res Treat 2006; 95:199-209. 